\title{
Article
}

\section{Atomic Layer Deposition of TiO on Aerogel Templates: New Photoanodes for Dye-Sensitized Solar Cells}

Thomas W. Hamann, Alex B. F. Martinson, Jeffrey W. Elam, Michael J. Pellin, and Joseph T. Hupp J. Phys. Chem. C, 2008, 112 (27), 10303-10307• DOI: 10.1021/jp802216p • Publication Date (Web): 18 June 2008

Downloaded from http://pubs.acs.org on March 2, 2009

\section{More About This Article}

Additional resources and features associated with this article are available within the HTML version:

- $\quad$ Supporting Information

- $\quad$ Links to the 4 articles that cite this article, as of the time of this article download

- $\quad$ Access to high resolution figures

- $\quad$ Links to articles and content related to this article

- Copyright permission to reproduce figures and/or text from this article

View the Full Text HTML 


\title{
Atomic Layer Deposition of $\mathrm{TiO}_{2}$ on Aerogel Templates: New Photoanodes for Dye-Sensitized Solar Cells
}

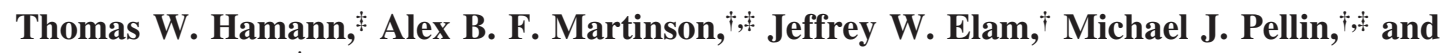 \\ Joseph T. Hupp*,:
}

Northwestern University, 2145 Sheridan Road, Evanston, Illinois 60208

Received: March 13, 2008; Revised Manuscript Received: April 25, 2008

\begin{abstract}
High surface area mesoporous aerogel films were prepared on conductive glass substrates. Atomic layer deposition was employed to coat the aerogel template conformally with various thicknesses of $\mathrm{TiO}_{2}$ with subnanometer precision. The $\mathrm{TiO}_{2}$-coated aerogel membranes were incorporated as photoanodes in dye-sensitized solar cells. The charge diffusion length was found to increase with increasing thickness of $\mathrm{TiO}_{2}$ leading to increasing current and efficiency. Initial devices exhibited power conversion efficiencies of up to $4.3 \%$ under $100 \mathrm{~W} \mathrm{~m}^{-2}$ light intensity. The novel fabrication technique provides a facile, oxide materials general method to prepare high surface area pseudo-one-dimensional DSSC photoanodes with promising performance.
\end{abstract}

\section{Introduction}

Dye-sensitized solar cells (DSSCs) based on nanocrystalline $\mathrm{TiO}_{2}$ have exhibited solar energy-conversion efficiencies up to $11 \%$ and are among one of the most promising candidates for cost-effective solar energy conversion devices. ${ }^{1,2}$ The excellent performance of the most efficient DSSCs reported to date is a consequence of good light harvesting combined with nearquantitative charge collection (at short circuit). ${ }^{1,3}$ The good light harvesting results from a combination of a moderate extinction dye with a high surface area photoanode. Because high chargecollection efficiency requires electron transport to be significantly faster than recombination, the slow (millisecond) electron transport through a nanoparticle photoanode demands even slower recombination. ${ }^{4}$ The excellent charge collection of the best devices to date has therefore relied on $\mathrm{I}^{-} / \mathrm{I}_{3}{ }^{-}$as the redox shuttle, since recombination to $\mathrm{I}_{3}{ }^{-}$via the complicated, and a presumably multielectron, process is exceedingly slow. ${ }^{4}$

The $\mathrm{I}_{3}{ }^{-} / \mathrm{I}^{-}$couple has several disadvantages, however, including limitations on the open-circuit voltage related to its redox potential. To advance device performance substantially beyond its current limits, the use of a new and energetically more favorable redox shuttle is likely necessary. Since all known alternative redox shuttles exhibit faster recombination kinetics, maintaining good charge collection efficiency will require concomitantly faster charge transport through the metal oxide framework. A straightforward way to accelerate charge transport is to reduce the dimensionality of charge diffusion.

Several interesting photoanode architectures based on $\mathrm{ZnO}$ have been fabricated with reduced dimensionality, notably $\mathrm{ZnO}$ nanorod arrays and $\mathrm{ZnO}$ nanotubes. ${ }^{5,6} \mathrm{ZnO}$ nanorod arrays have been shown to exhibit much faster charge transport than comparable $\mathrm{ZnO}$ nanoparticle networks as expected. ${ }^{7,8}$ While $\mathrm{ZnO}$ nanorod and nanotube devices have shown promising efficiencies of $1.5 \%$ and $1.6 \%$, respectively, further improvement requires overcoming the technical challenge of increasing the

\footnotetext{
* Corresponding author. E-mail: j-hupp@ northwestern.edu.

* Northwestern University.

${ }^{\dagger}$ Current address: Argonne National Laboratory, 9700 South Cass Avenue, Argonne, IL 60439.
}

relatively low surface area that currently limits light-harvesting. In addition, $\mathrm{ZnO}$ devices generally exhibit lower efficiencies than comparable $\mathrm{TiO}_{2}$ devices due, at least in part, to corrosion and/or nonideal dye loading. ${ }^{9}$ Arrays of $\mathrm{TiO}_{2}$ nanotubes have recently been employed as a reduced dimension photoanode architecture in DSSCs, exhibiting power conversion efficiencies up to $7 \% .{ }^{10}$ Surprisingly, the nanotube films displayed similar transport times to comparable nanoparticle films; however, recombination was found to be slower in the nanotube films. ${ }^{10}$

Here we introduce a new core-shell pseudo-one-dimensional $\mathrm{TiO}_{2}$ photoanode design featuring high aspect ratio structures incorporated in DSSCs. Inert low-density, high-surface-area silica aerogel films are prepared as substructure templates. ${ }^{11,12}$ The aerogel templates are coated with $\mathrm{TiO}_{2}$ via atomic layer deposition (ALD) to yield an electrically interconnected semiconductor core-shell nanoweb structure. ${ }^{13-15}$ Because it is both a stepwise and conformal coating technique, ALD provides exceptional control over nanoscale device composition. The large number of materials accessible by ALD (including, but not limited to, $\mathrm{TiO}_{2}, \mathrm{ZnO}, \mathrm{SnO}_{2}, \mathrm{ZrO}_{2}$, and $\mathrm{NiO}$ ) makes the technique widely applicable for the development of new photoelectrodes. ${ }^{16}$ In addition, new mixed metal oxides have recently attracted attention as materials for DSSC photoelectrodes which should be readily implemented utilizing the templating strategy in conjunction with ALD. ${ }^{17}$ Herein we demonstrate the viability of $\mathrm{TiO}_{2}$ versions of these structures as dye-sensitized electrodes by characterizing their morphology and photovoltaic performance. In a related report we have described the behavior of DSSC photoelectrodes comprising zinc oxide on silica aerogels. ${ }^{18}$

\section{Experimental Section}

All chemicals, unless noted otherwise, were purchased from Aldrich and used as received.

Aerogel films were prepared as follows. A silica solution was prepared by diluting a prehydrolyzed ethyl polysilicate solution (Silbond Corp.) to $50 \%$ by volume with ethanol. One volume equivalent of a catalyst solution $\left(50 \mathrm{~mL}\right.$ of $\mathrm{H}_{2} \mathrm{O}, 40 \mathrm{~mL}$ of ethanol, $1.6 \mathrm{~mL}$ of $30 \% \mathrm{NH}_{4} \mathrm{OH}$ ) was slowly added while 
stirring to the silica solution to form the sol. Prior to the gel point, typically $10 \mathrm{~min}$ after addition of the catalyst, the sol was dropcast onto fluorine-doped tin oxide, FTO, substrates inside a controlled atmosphere chamber saturated with vapor from 1:1 v:v ethanol:water solution. The gel point was approximately $20 \mathrm{~min}$. Following gelation, substrates were immersed in catalyst solution and allowed to react an additional $12 \mathrm{~h}$. The resulting alcogel films were exchanged with ethanol three times to remove residual water and dried with supercritical $\mathrm{CO}_{2}$. The aerogel active areas were approximately $0.25 \mathrm{~cm}^{2}$, defined by scraping with a razor blade.

Atomic layer deposition was performed with a Savannah 100 instrument (Cambridge Nanotech Inc.), using titanium isopropoxide and water as precursors. $\mathrm{TiO}_{2}$ was grown at $200{ }^{\circ} \mathrm{C}$, using reactant exposure times of 14 and $7 \mathrm{~s}$ for titanium isopropoxide and $\mathrm{H}_{2} \mathrm{O}$, respectively, and nitrogen purge times of $30 \mathrm{~s}$ between exposures. The $\mathrm{TiO}_{2}$ coated films were annealed at $500{ }^{\circ} \mathrm{C}$ in air for $20 \mathrm{~min}$ to increase crystallinity.

After heating, the substrates were cooled to $100{ }^{\circ} \mathrm{C}$ and immediately immersed in $0.5 \mathrm{mM}\left(\mathrm{Bu}_{4} \mathrm{~N}\right)_{2}\left[\mathrm{Ru}\left(4,4^{\prime}-(\mathrm{COOH})\right.\right.$ 2,2'-bipyridine $)_{2}(\mathrm{NCS})_{2}$ ] ("N719", Dyesol, B2 dye) in ethanol. After $\sim 20 \mathrm{~h}$, they were rinsed with ethanol and dried with $\mathrm{N}_{2}$. A Surlyn frame was sandwiched between the open-pore side of the membrane and a platinized FTO electrode. Light pressure was applied at $130{ }^{\circ} \mathrm{C}$ to seal the cell. A solution of $0.60 \mathrm{M}$ butylmethylimidazolium iodide, $0.03 \mathrm{M} \mathrm{I}_{2}, 0.10 \mathrm{M}$ guanidinium thiocyanate, and $0.50 \mathrm{M}$ 4-tert-butylpyridine in acetonitrile: valeronitrile (85:15) was introduced into the $\mathrm{TiO}_{2}$ cells. Additional Surlyn and a microscope coverslip sealed the electrolyte into the cell. The active area was masked with tape and the electrode area measured with calipers.

AM 1.5 efficiencies were measured on a Class A solar cell analyzer from Spectra-Nova Technologies with a power of $\sim 99$ $\mathrm{mW} / \mathrm{cm}^{2}$. Absorbances were measured with a Varian Cary 5000 UV-vis spectrometer. Film thicknesses were measured on a Tencor P10 profilometer. Scanning electron microscopy (SEM) images were collected on a Hitachi S-4800-II cFEG SEM. Micro-Raman spectrometry was performed by using a Renishaw RM2000 Raman Microprobe. This system is equipped with a $\mathrm{He}-\mathrm{Ne}$ laser with a wavelength of $632 \mathrm{~nm}$ and was used to obtain Raman spectra of the samples in the range 100-700 $\mathrm{cm}^{-1}$. The diameter of the focused laser beam was approximately $2 \mu \mathrm{m}$.

For surface area measurements via gas adsorption, photoelectrodes not yet exposed to dye were loaded into a sample tube and evacuated at $200{ }^{\circ} \mathrm{C}$ under $10^{-5}$ Torr of dynamic vacuum for $24 \mathrm{~h}$ on an Autosorb 1-MP volumetric sorption apparatus prior to gas adsorption measurements. Nitrogen and Krypton isotherms were collected at $77 \mathrm{~K}$.

\section{Results and Discussion}

The porosity of aerogels is known to be controlled by the concentration of the sol and can exceed 99.5\%. ${ }^{11,12,19}$ The aerogel films in this study were prepared with sols to make highly porous structures $(>90 \%)$ leaving volume for growth of sufficiently thick $\mathrm{TiO}_{2}$ layers without completely filling the aerogel pores. The amount of sol dropcast onto the FTO substrate in general determines the thickness of the resulting aerogel film. All films examined here were prepared in a single dropcast. Aerogel films are approximately $25 \mu \mathrm{m}$ thick, as determined from profilometry and SEM.

The aerogel films are extremely fragile as prepared; however, after coating with even a thin layer $(\sim 2 \mathrm{~nm})$ of semiconductor they were found to be much more robust. A series of $\sim 25 \mu \mathrm{m}$
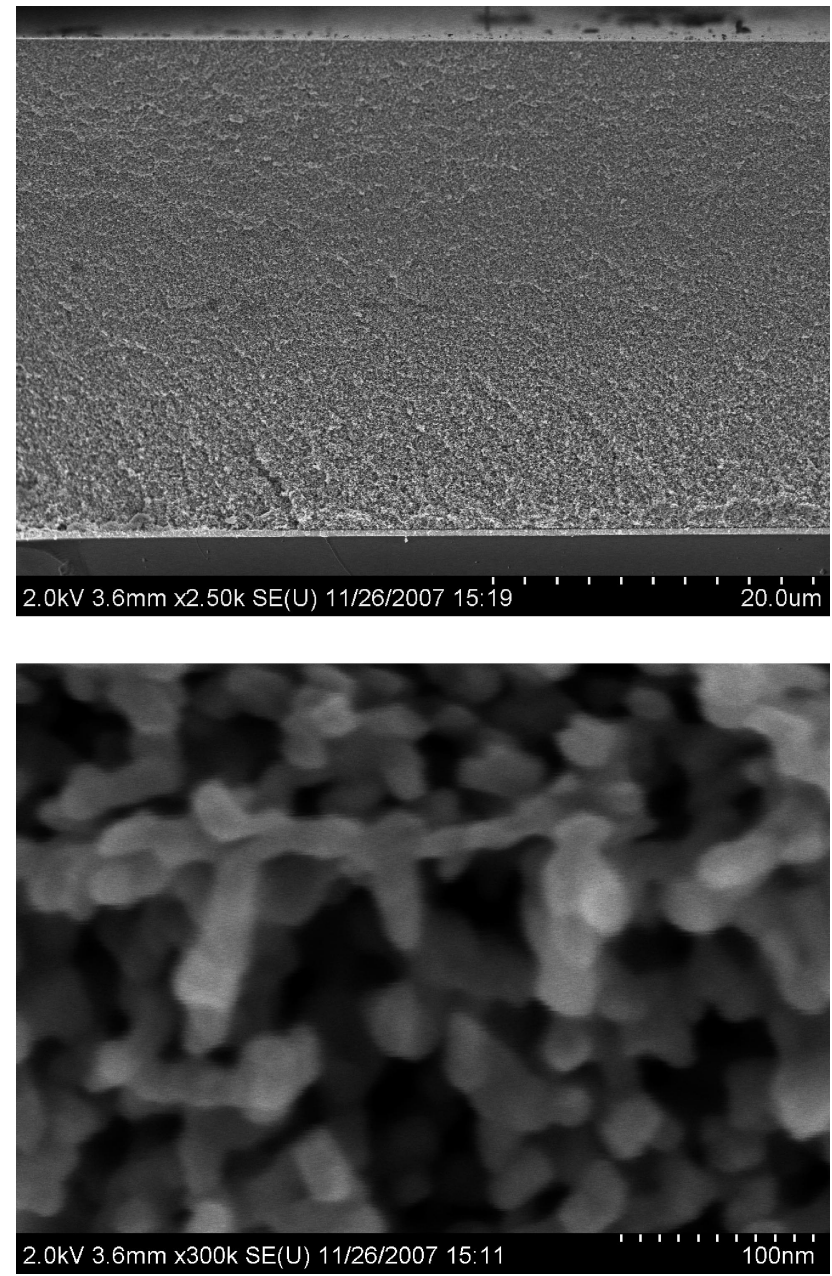

Figure 1. SEM images of a $\sim 30 \mu \mathrm{m}$ thick aerogel film coated with $9.6 \mathrm{~nm} \mathrm{TiO}_{2}$.

thick aerogel films were coated with $\mathrm{TiO}_{2}$ via 70, 140, 210, 280 , or 350 ALD cycles. The thickness of deposited $\mathrm{TiO}_{2}$ was determined by elipsometry measurements of flat silicon substrates that were coated concurrently. The measured thickness of $\mathrm{TiO}_{2}$ deposited as a function of ALD cycles is linear, with a slope of $0.34 \AA /$ cycle, in good agreement with literature reports. ${ }^{20-22}$ The aerogel films were thus coated with approximately $2.4,4.8,7.2,9.6$, and $12 \mathrm{~nm}$ of $\mathrm{TiO}_{2}$. The aerogel films are initially transparent then become opaque-white due to scattering by thicker layers $(>5 \mathrm{~nm}$ ) of high-refractive index $\mathrm{TiO}_{2}$. Raman spectra were taken of an aerogel film coated with $9.6 \mathrm{~nm}$ of $\mathrm{TiO}_{2}$ as prepared and after annealing at $500{ }^{\circ} \mathrm{C}$ for $30 \mathrm{~min}$ (see the Supporting Information). $\mathrm{The}^{\mathrm{TiO}}{ }_{2}$ appears to be amorphous as deposited, but the Raman peaks at 396, 519, and $638 \mathrm{~cm}^{-1}$ indicate transformation to anatase upon annealing. ${ }^{23}$

Figure 1 shows cross-sectional SEM images of a $\sim 30 \mu \mathrm{m}$ thick aerogel film coated with $9.6 \mathrm{~nm}$ (280 cycles) of $\mathrm{TiO}_{2}$. From the image it is clear that the aerogel film remains very porous after coating. In addition, the feature size of the coated aerogels closely matches twice the thickness of the deposited $\mathrm{TiO}_{2}$ indicating that the original silica aerogel framework takes up, as expected, a small amount of space.

A monolithic aerogel sample was prepared from the same solution as the films, in a nominally identical fashion, and coated with $9.6 \mathrm{~nm}$ of $\mathrm{TiO}_{2}$. Figure $2 \mathrm{a}$ shows a $\mathrm{N}_{2}$ adsorption isotherm of the bulk sample $\left(\mathrm{N}_{2}\right.$ measurements lack the sensitivity required for relatively low absolute surface-area thin films). The 
a)

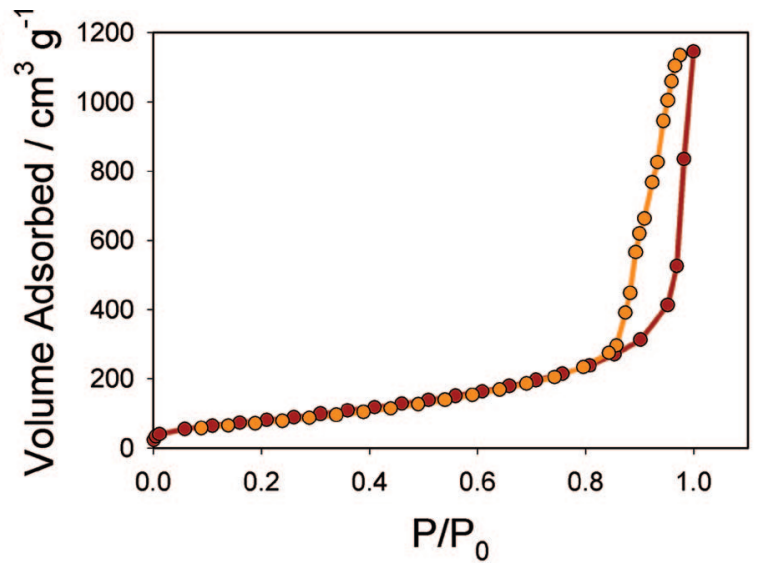

b)

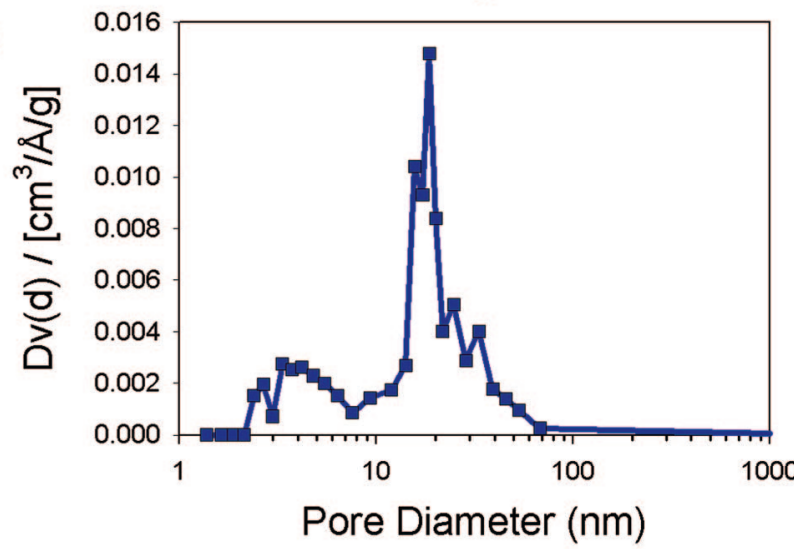

c)

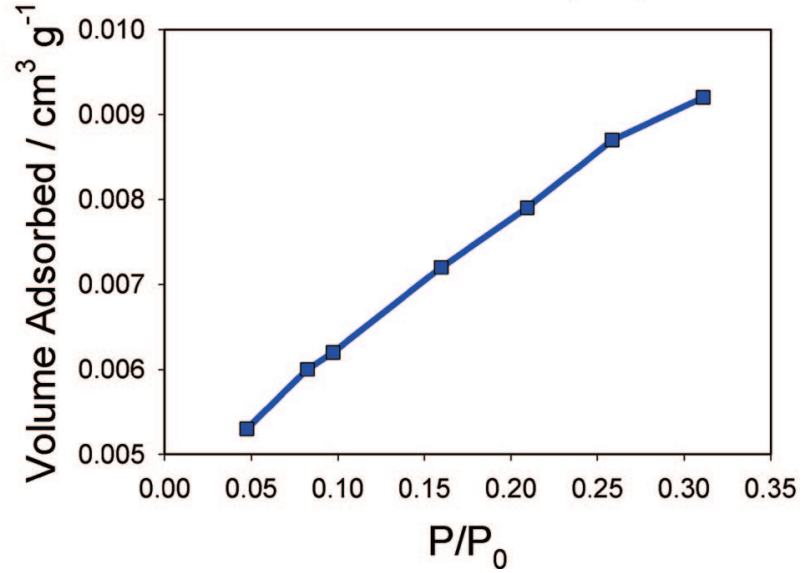

Figure 2. Plots of the (a) $\mathrm{N}_{2}$ adsorption (red) and desorption (orange) isotherm of a bulk aerogel sample coated with $9.6 \mathrm{~nm} \mathrm{TiO}_{2}$; (b) pore size distribution of the bulk sample; and (c) $\mathrm{Kr}$ adsorption isotherm of an aerogel film coated with $9.6 \mathrm{~nm} \mathrm{TiO}_{2}$.

BET surface area of the $\sim 10 \mathrm{mg}$ sample was $310 \mathrm{~m}^{2} \mathrm{~g}^{-1}$, within the range previously reported for bulk aerogels. ${ }^{24,25}$ The desorption curve shows a distinct hysteresis and is indicative of mesoporosity. The Dollimore and Heal (DH) method was used to calculate the pore size distribution, Figure $2 b$. The distribution is bimodal, with a most prevalent pore size diameter of $\sim 20 \mathrm{~nm}$. Also clearly present in the distribution are pores of ca. 2-7 nm diameter. The smallest of the pores conceivably could be problematic for dye loading, so may not be ideal for a photoanode.

Krypton adsorption measurements offer roughly 20 -fold better sensitivity than $\mathrm{N}_{2}$ measurements, thereby allowing individual thin films to be characterized directly (unfortunately, $\mathrm{Kr}$ adsorption measurements do not allow pore size distributions to be determined). Shown in Figure $2 \mathrm{c}$ is a $\mathrm{Kr}$ adsorption

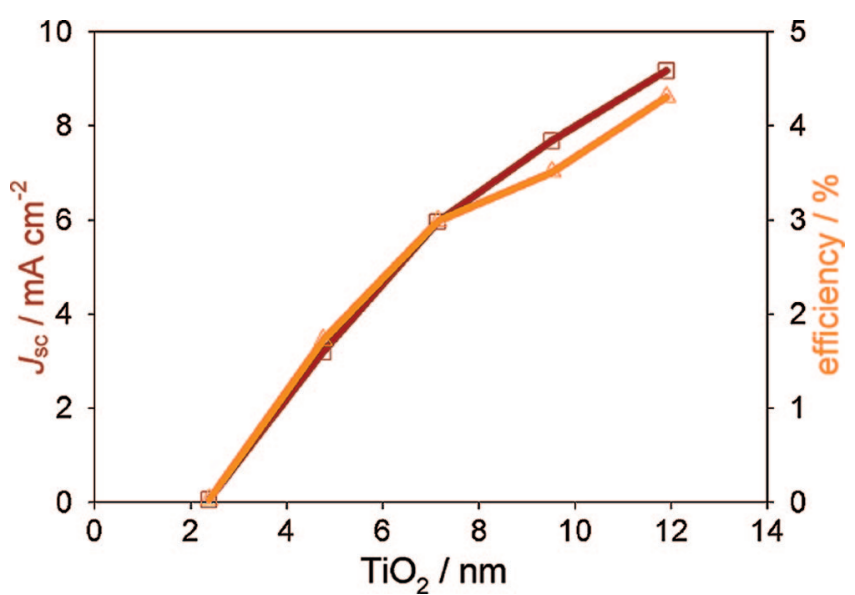

Figure 3. Plots of the short circuit current density (red), $J_{\mathrm{sc}}$, and efficiency (orange), $\eta$, as a function of thickness of $\mathrm{TiO}_{2}$ deposited on aerogel films.

TABLE 1: Measured Photovoltaic Parameters for a Series of $25 \mu \mathrm{m}$ Thick Aerogel Films Coated with $\mathrm{TiO}_{2}$

\begin{tabular}{cccccl}
\hline ALD cycles & $\mathrm{TiO}_{2}(\mathrm{~nm})$ & $J_{\mathrm{sc}}\left(\mathrm{mA} \mathrm{cm}^{-2}\right)$ & $V_{\mathrm{oc}}(\mathrm{V})$ & $\mathrm{FF}$ & $\eta(\%)$ \\
\hline 70 & 2.4 & 0.06 & 0.63 & 0.67 & 0.02 \\
140 & 4.8 & 3.19 & 0.70 & 0.77 & 1.7 \\
210 & 7.2 & 5.96 & 0.67 & 0.74 & 3.0 \\
280 & 9.6 & 7.68 & 0.68 & 0.67 & 3.5 \\
350 & 12 & 9.17 & 0.67 & 0.69 & 4.3
\end{tabular}

isotherm of a single $25 \mu \mathrm{m}$ thick aerogel film coated with 9.6 $\mathrm{nm}$ (280 cycles) of $\mathrm{TiO}_{2}$. The $0.25 \mathrm{~cm}^{2}$ film had a surface area of $\sim 400 \mathrm{~cm}^{2}$ (see the Supporting Information for the BET plot) indicating a roughness factor of $\sim 1,600\left(64 \mathrm{~cm}^{2} / \mu \mathrm{m}\right)$. Roughness factors equaling or exceeding those of typical nanoparticle electrodes $(\sim 1,200)$ are thus clearly obtainable.

Dye molecules were desorbed via immersion in $10 \mathrm{mM}$ $\mathrm{NaOH}(\mathrm{aq})$ solution from a series of nominally identical aerogel electrodes coated with 2.4, 4.8, 7.2, 9.6, or $12 \mathrm{~nm}$ of $\mathrm{TiO}_{2}$. The absorbance of desorbed dye for all samples, correcting for differences in electrode area, was essentially constant across the series. The small differences in dye loading were not systematic and are thus attributed to random variations in the aerogel morphology. Approximating the $\mathrm{TiO}_{2}$-coated aerogel structure as a series of interconnected spheres and cylinders, the surface area should increase linearly with $\mathrm{TiO}_{2}$ deposited, but decrease due to filling in pores and necks. Apparently, these two mechanisms effectively offset each. Photoelectrode roughness can also be estimated by dye desorption, which results in roughness factors of $\sim 1,000 .{ }^{26}$ Estimating roughness by dye desorption excludes any part of the aerogel surface area inaccessible to dye, for example, topological features that are simply smaller than the dye. Such features may account for the difference in surface areas obtained for dye versus gas molecule adsorption.

Figure 3 shows the short circuit-current density, $J_{\mathrm{sc}}$, and power conversion efficiency, $\eta$, as a function of thickness of $\mathrm{TiO}_{2}$ deposited on a series of aerogel films. The current collected for films coated with less than $4 \mathrm{~nm}$ of $\mathrm{TiO}_{2}$ is small; however, the current increases with increasing thickness of $\mathrm{TiO}_{2}(\mathrm{Table}$ 1). The current density and efficiency continue to increase with the thickest layers of $\mathrm{TiO}_{2}$ deposited indicating that more $\mathrm{TiO}_{2}$ would likely lead to further increases in current and efficiency. The linear plot of $J_{\mathrm{sc}}$ vs light intensity (see the Supporting Information) indicates mass transport through the $\mathrm{TiO}_{2}$-coated aerogel membrane is not a limiting factor, in contrast to a similar 


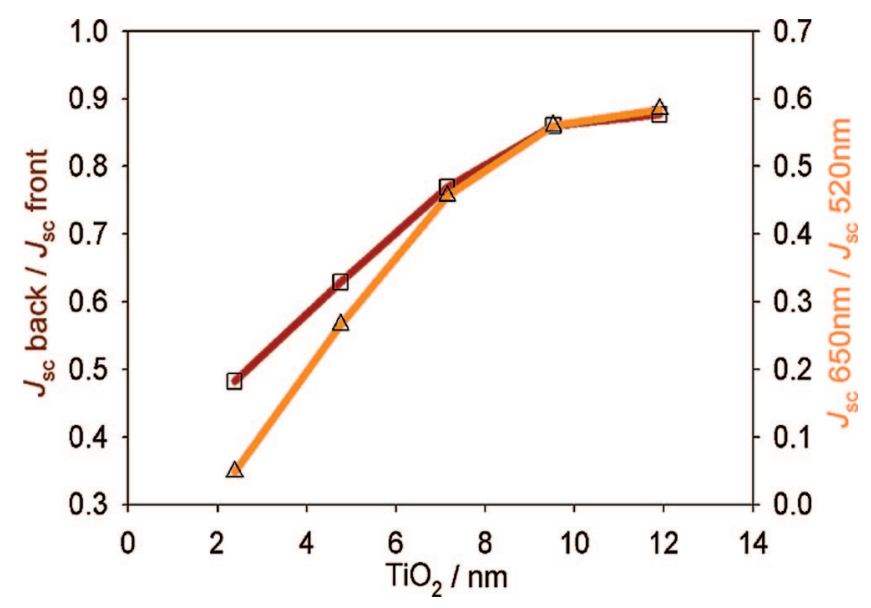

Figure 4. Plot of short-circuit current density, $J_{\mathrm{sc}}$, ratios of illumination through the cathode to photoanode (red) and illumination with $650 \mathrm{~nm}$ light to $520 \mathrm{~nm}$ light (orange).

report on $\mathrm{ZnO}$-coated aerogel templates, which exhibited mass transport limited current densities when $>8 \mathrm{~nm}$ layers of $\mathrm{ZnO}$ were deposited. Attempts to deposit additional $\mathrm{TiO}_{2}$, however, have thus far resulted in buckling or delamination of the aerogel films from the FTO substrate. A similar trend of increasing current with $\mathrm{TiO}_{2}$ thickness deposited by ALD was reported for $\mathrm{TiO}_{2}$ coatings on $\mathrm{ZnO}$ nanorods and was attributed to increasing crystallinity of the deposited $\mathrm{TiO}_{2}$ resulting in better injection or charge transport. ${ }^{27}$

Increasing rates of charge transport with increasing ALD coating thickness should translate into longer diffusion lengths, assuming constant or decreasing recombination rates. Relative diffusion lengths can be estimated by comparing $J_{\mathrm{sc}}$ values from frontside (photoanode) vs backside (semitransparent cathode) illumination. Approximately $50 \%$ as much current is collected for the sample with $2.4 \mathrm{~nm}$ of $\mathrm{TiO}_{2}$ when illuminated through the cathode compared to the photoanode. The ratio of photocurrents from cathode vs photoanode illumination increases with the thickness of $\mathrm{TiO}_{2}$ deposited, reaching $\sim 90 \%$ for samples with $\geq 10 \mathrm{~nm}$ of $\mathrm{TiO}_{2}$, Figure 4 . The measurements of illumination through the cathodes were not corrected for light attenuation due to the Pt-coated cathode, bulk electrolyte solution, and partial coverage of the photoelectrode by the hole used to introduce electrolyte, which together can account for $\sim 10-20 \%$ decreased $J_{\text {sc }}$. The observed increasing ratio of photocurrents indicates that the diffusion length is increasing with semiconductor thickness, and that the diffusion length is greater than the electrode thickness once a threshold amount of $\sim 10 \mathrm{~nm} \mathrm{TiO}_{2}$ is deposited.

Since dye loading is essentially constant for the different thicknesses of $\mathrm{TiO}_{2}$ deposited, relative diffusion lengths, $L_{\mathrm{n}}$, can also be estimated by comparing the incident photon-to-current efficiency, IPCE, in different spectral regions. The IPCE is given by $\operatorname{IPCE}(\lambda)=\operatorname{LHE}(\lambda) \times \Phi_{\text {inj }} \times \eta_{\mathrm{c}}$, where LHE is the lightharvesting efficiency at a given wavelength, $\Phi_{\text {inj }}$ is the electron injection efficiency, and $\eta_{\mathrm{c}}$ is the charge collection efficiency. The LHE is the fraction of photons absorbed at that wavelength; it can be described by using Beers law in the form LHE = $1-10^{-\varepsilon(\lambda) L_{\mathrm{n}} C}$, where $\epsilon(\lambda)$ is the extinction coefficient and $C$ is concentration. Assuming that the electron injection and charge collection efficiencies are independent of photon wavelength, the ratio of IPCEs at wavelengths associated with different extinction coefficients will vary with $L_{\mathrm{n}}$ until $L_{\mathrm{n}}$ is greater than or equal to the total film thickness $(\sim 25 \mu \mathrm{m})$. Comparison of the ratios of IPCE at different wavelengths has the virtue of

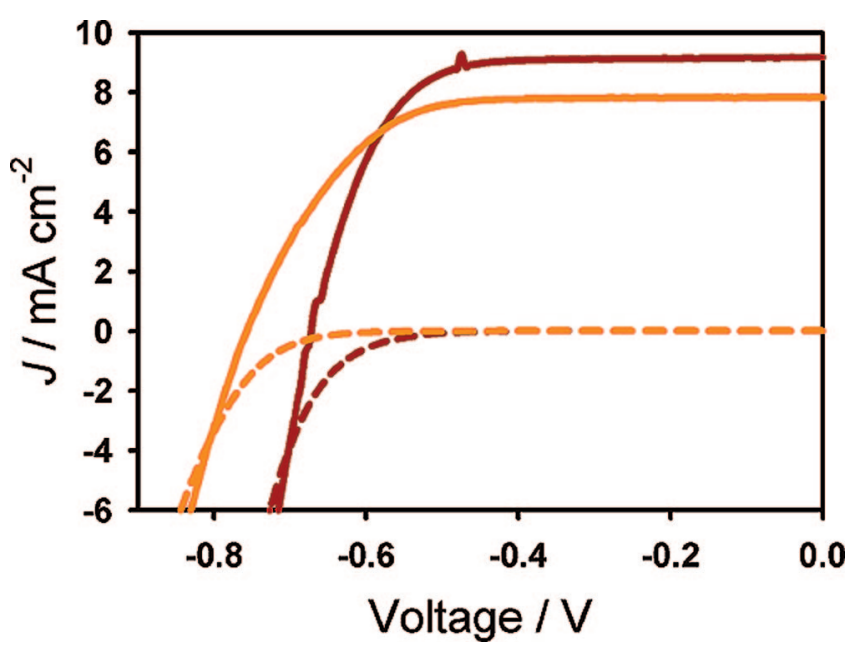

Figure 5. Plot of $J-V$ curves for an aerogel electrode coated with 12 $\mathrm{nm} \mathrm{TiO}_{2}$ (Red) and $\mathrm{TiO}_{2}$ nanoparticle (orange) in the dark (dasked lines) and under AM 1.5 illumination (solid).

canceling any effects due to thickness-dependent injection efficiencies (potentially an issue for the thinnest $\mathrm{TiO}_{2}$ layers).

Figure 4 shows the ratio of $J_{\mathrm{sc}}$ collected for illumination with $650 \mathrm{~nm}$ light and $520 \mathrm{~nm}$ light. The ratio increases with the thickness of $\mathrm{TiO}_{2}$, following the same trend of the ratio of $J_{\mathrm{sc}}$ from illumination through the cathode vs. photoanode. Taken together, the trends of increasing $J_{\text {sc }}$ ratios with $\mathrm{TiO}_{2}$ thickness provide strong evidence that the observation of increasing current and efficiency with $\mathrm{TiO}_{2}$ thickness shown in Figure 3 is due to increasing charge diffusion length. Further, once a sufficient amount of $\mathrm{TiO}_{2}$ is deposited, $\sim 10 \mathrm{~nm}$, the diffusion length is longer than the film thickness and electrons can be collected efficiently from throughout the $25 \mu \mathrm{m}$ thick film.

A standard $10 \mu \mathrm{m}$ thick $\mathrm{TiO}_{2}$ nanoparticle photoanode was prepared for comparison. Surface treatment of the nanoparticles with $\mathrm{TiCl}_{4}$ and an additional layer of large particles used for light scattering have been shown to increase light harvesting, and thus $J_{\mathrm{sc}}$, but were omitted here to allow for a direct comparison of the two different $\mathrm{TiO}_{2}$ architectures. Figure 5 shows the $J-V$ curves for DSSCs fabricated by using photoanodes of an aerogel coated with $12 \mathrm{~nm}$ of $\mathrm{TiO}_{2}$ and nanoparticles. The aerogel-templated photoanode exhibits somewhat higher $J_{\mathrm{sc}}$ and lower $V_{\mathrm{oc}}$ (due to the larger dark current) than the nanoparticle photoanode, but comparable efficiency. The larger $J_{\mathrm{sc}}$ and dark current (and thus lower $V_{\mathrm{oc}}$ ) for the aerogeltemplated photoanode are attributed to the very large surface area.

\section{Conclusion}

A new pseudo-one-dimensional architecture for DSSC photoanodes was prepared by using templates of low-density, high surface area, mesoporous aerogel thin films. $\mathrm{TiO}_{2}$ was conformally deposited with a controlled variable thickness on aerogel templates by ALD. The cell efficiency was found to increase with increasing thickness of $\mathrm{TiO}_{2}$ deposited due to increasing charge diffusion lengths. The electrodes incorporated into DSSCs displayed good light harvesting and excellent power efficiencies compared with nanoparticle $\mathrm{TiO}_{2}$ based DSSCs. The promising initial performance reported herein, the ease of fabrication, materials generality, and the flexibility of design make ALD-coated aerogel-templated photoanodes a promising candidate to move beyond nanoparticle electrodes in DSSCs.

Acknowledgment. The SEM work was performed in the EPIC facility of NUANCE Center at Northwestern University. 
The NUANCE Center is supported by NSF-NSEC, NSFMRSEC, Keck Foundation, the State of Illinois, and Northwestern University. We gratefully acknowledge financial support from BP Solar, Argonne National Laboratory (fellowship for ABFM), and the U.S. Department of Energy, Basic Energy Sciences Program (Grant DE-FG02-87ER13808). Work at Argonne was performed under Contract No. DE-AC0206CH11357 with the U.S. Department of Energy. We thank Tobin Marks for use of the solar cell analyzer.

Supporting Information Available: MicroRaman spectra of $\mathrm{TiO}_{2}$ on aerogel templates, plot of short-circuit current density, $J_{\mathrm{sc}}$, in response to white light illumination at different intensities, and BET plot of the $\mathrm{Kr}$ adsorption isotherm of an aerogel film. This material is available free of charge via the Internet at http://pubs.acs.org.

\section{References and Notes}

(1) Gratzel, M. Inorg. Chem. 2005, 44, 6841-6851.

(2) Nazeeruddin, M. K.; De Angelis, F.; Fantacci, S.; Selloni, A.; Viscardi, G.; Liska, P.; Ito, S.; Takeru, B.; Gratzel, M. G. J. Am. Chem. Soc. 2005, 127, 16835-16847.

(3) Kroon, J. M.; Bakker, N. J.; Smit, H. J. P.; Liska, P.; Thampi, K. R.; Wang, P.; Zakeeruddin, S. M.; Gratzel, M.; Hinsch, A.; Hore, S.; Wurfel, U.; Sastrawan, R.; Durrant, J. R.; Palomares, E.; Pettersson, H.; Gruszecki, T.; Walter, J.; Skupien, K.; Tulloch, G. E. Prog. Photovoltaics 2007, 15, $1-18$.

(4) Peter, L. M. J. Phys. Chem. C 2007, 111, 6601-6612.

(5) Law, M.; Greene, L. E.; Johnson, J. C.; Saykally, R.; Yang, P. D. Nat. Mater. 2005, 4, 455-459.

(6) Martinson, A. B. F.; Elam, J. W.; Hupp, J. T.; Pellin, M. J. Nano Lett. 2007, 7, 2183-2187.

(7) Martinson, A. B. F.; McGarrah, J. E.; Parpia, M. O. K.; Hupp, J. T. Phys. Chem. Chem. Phys. 2006, 8, 4655-4659.

(8) Galoppini, E.; Rochford, J.; Chen, H. H.; Saraf, G.; Lu, Y. C.; Hagfeldt, A.; Boschloo, G. J. Phys. Chem. B 2006, 110, 16159-16161.

(9) Quintana, M.; Edvinsson, T.; Hagfeldt, A.; Boschloo, G. J. Phys. Chem. C 2007, 111, 1035-1041.
(10) Zhu, K.; Neale, N. R.; Miedaner, A. Frank, A. J. Nano Lett. 2007, 7, 69-74. Shankar, K.; Mor, G. K.; Prakasam, H. E.; Yoriya, S.; Paulose, M.; Varghese, O. K.; Grimes, C. A. Nanotechnology, 2007, 18, 065707.

(11) Akimov, Y. K. Instrum. Exp. Tech. 2003, 46, 287-299.

(12) Fricke, J.; Tillotson, T. Thin Solid Films 1997, 297, 212-223.

(13) Elam, J. W.; Xiong, G.; Han, C. Y.; Wang, H. H.; Birrell, J. P.; Welp, U.; Hryn, J. N.; Pellin, M. J.; Baumann, T. F.; Poco, J. F.; Satcher, J. J. H. J. Nanomater. 2006, 2006, 1.

(14) Elam, J. W.; Libera, J. A.; Pellin, M. J.; Zinovev, A. V.; Greene, J. P.; Nolen, J. A. Appl. Phys. Lett. 2006, 89.

(15) Kucheyev, S. O.; Biener, J.; Wang, Y. M.; Baumann, T. F.; Wu, K. J.; van Buuren, T.; Hamza, A. V.; Satcher, J. H.; Elam, J. W.; Pellin, M. J. Appl. Phys. Lett. 2005, 86.

(16) Ritala, M.; Leskela, M. Handbook of Thin Film Materials; Academic Press: San Diego, CA, 2001; Vol. 1.

(17) Tan, B.; Toman, E.; Li, Y. G.; Wu, Y. Y. J. Am. Chem. Soc. 2007, $129,4162-4163$.

(18) Hamann, T. W.; Martinson, A. B. F.; Elam, J. W.; Pellin, M. J.; Hupp, J. T. Adv. Mater. 2008, 20, 1560-1564.

(19) Akimov, Y. K. Instrum. Exp. Tech. 2003, 46, 287-299.

(20) Aarik, J.; Aidla, A.; Uustare, T.; Ritala, M.; Leskela, M. Appl. Surf. Sci. 2000, 161, 385-395.

(21) Rahtu, A.; Ritala, M. Chem. Vapor Depos. 2002, 8, 21-28.

(22) Xie, Q.; Jiang, Y. L.; Detavernier, C.; Deduytsche, D.; Van Meirhaeghe, R. L.; Ru, G. P.; Li, B. Z.; Qu, X. P. J. Appl. Phys. 2007, 102.

(23) Toshiaki Ohsaka, F. I. Y. F. J. Raman Spectrosc. 1978, 7, 321324.

(24) Husing, N.; Schubert, U. Angew. Chem., Int. Ed. 1998, 37, $23-45$.

(25) Brunauer, S.; Emmett, P. H.; Teller, E. J. Am. Chem. Soc. 1938, $60,309-319$.

(26) Assuming the dye, with a diameter of $1.4 \mathrm{~nm}$, occupies an area of $2 \times 10^{-14} \mathrm{~cm}^{2}$, a flat electrode of area $0.25 \mathrm{~cm}^{2}$ can therefore accommodate $\sim 10^{13}$ dye molecules. The absorbance from the dye desorbed by $3 \mathrm{~mL}$ of $0.01 \mathrm{M} \mathrm{NaOH}$ was typically 0.1 at $535 \mathrm{~nm}$. The N719 extinction coefficient at $535 \mathrm{~nm}$ is $1.47 \times 10^{4} \mathrm{~L} \mathrm{~mol}^{-1}$, thus an absorbance of 0.1 indicates a concentration of $7 \times 10^{-6} \mathrm{M}$ or $\sim 10^{16}$ dye molecules. The roughness is thus approximately $\left(10^{16 / 10^{13}}\right)=1000$

(27) Law, M.; Greene, L. E.; Radenovic, A.; Kuykendall, T.; Liphardt, J.; Yang, P. D. J. Phys. Chem. B 2006, 110, 22652-22663.

JP802216P 